\title{
Queda do crescimento demográfico da Amazônia colombiana: possíveis reflexos do fim do conflito bélico
}

\section{Falling demographic growth of the Colombian Amazon: possible reflexes of the end of the war conflict}

Luis E. Aragón - Ph.D. em Geografia, pela Michigan State University. Professor titular do Núcleo de Altos Estudos Amazônicos (NAEA) da Universidade Federal do Pará (UFPA). Bolsista de produtividade do CNPq e coordenador da Cátedra UNESCO/UFPA de Cooperação Sul-Sul para o Desenvolvimento Sustentável. E-mail: aragon_naea@ufpa.br

\section{Resumo}

$\mathrm{Na}$ Colômbia, ao longo de mais de 50 anos, uma guerra civil flagelou o país no conflito bélico mais longo da história contemporânea da América Latina, conflito que cessou em 2016, com a assinatura do acordo de paz entre as FARC-EP e o governo colombiano. O objetivo central deste artigo é descrever o crescimento demográfico da Amazônia colombiana conforme os últimos quatro censos (1985, 1993, 2005 e 2018), identificando possíveis relações entre a implantação do acordo e a queda contínua do ritmo de crescimento da população da Amazônia. Com as expectativas criadas pelo acordo, esperava-se um aumento significativo da população regional no censo de 2018, mas isso não se confirma. Existe uma associação inversa entre taxas de crescimento e intensidade de expulsão de deslocados forçados, indicando que as pessoas não estão retornando às áreas anteriormente dominadas pela guerrilha, como previsto no acordo, podendo levá-lo ao fracasso.

\section{Palavra-chave}

Amazônia Colombiana. FARC. Deslocamento Forçado. Crescimento Demográfico.

\section{Abstract}

In Colombia, for more than 50 years, a civil war has plagued the country in the longest military conflict in contemporary Latin American history, a conflict that ended in 2016, with the signing of the peace agreement between the FARCEP and the Colombian government. The central objective of this article is to describe the demographic growth of the Colombian Amazon according to the last four censuses $(1985,1993,2005$ and 2018), identifying possible relationships between the implementation of the agreement and the continuous decline in the growth rate of the population of the Amazon. With the expectations created by the agreement, a significant increase in the regional population was expected in the 2018 census, but this is not confirmed. There is an inverse association between growth rates and the intensity of expulsion of forced displaced persons, indicating that people are not returning to areas previously dominated by the guerrillas, as was foreseen by the agreement, putting it at risk of failure.

\section{Keywords}

Colombian Amazon. FARC. Forced Displacement. Demographic Growth. 


\section{INTRODUÇÃO}

$\mathrm{Na}$ Colômbia, ao longo de mais de 50 anos, uma guerra civil flagelou o país no conflito bélico mais longo da história contemporânea da América Latina. Segundo o Alto Comisariado de las Naciones Unidas para los Refugiados (ACNUR, 2019, p. 6), estima-se que o conflito deixou mais de 220 mil mortos e cerca de 8 milhões de deslocados forçados no país, sendo que a Amazônia foi uma das regiões onde a guerrilha denominada Forças Armadas Revolucionárias da Colômbia - Exército do Povo (FARC-EP) teve grande expressão, como indica o Observatorio de la Consejería Presidencial para los Derechos Humanos (OCPDH, 2015). Mas o conflito cessou, pelo menos formalmente, em novembro de 2016, com a assinatura do acordo de paz entre as FARC-EP e o governo colombiano. É urgente, portanto, identificar as mudanças pelas quais está passando a Amazônia colombiana neste momento de transição pós-conflito bélico. Nesse sentido, o objetivo central deste artigo $^{1}$ é descrever o crescimento demográfico da Amazônia colombiana conforme os últimos quatro censos (1985, 1993, 2005 e 2018), identificando possíveis reflexos do fim do conflito bélico. Pretende-se, mais que explicar, explorar possíveis relações entre a implantação do acordo de paz e a queda contínua do ritmo de crescimento da população da região amazônica colombiana.

O artigo consta de seis partes, sendo a primeira esta Introdução. A segunda parte descreve a delimitação da Amazônia colombiana utilizada no artigo considerando que na Colômbia não existe consenso sobre a delimitação da região. A terceira parte expõe a história da ocupação da Amazônia para contextualizar o processo de crescimento demográfico e o conflito armado, a produção de coca, e outros fatos relevantes da história da região. Na quarta parte se descreve o crescimento demográfico da Amazônia conforme os últimos quatro censos (1985, 1993, 2005 e 2018). A quinta parte é dedicada à quantificação e breve análise dos dados oficiais sobre deslocamento forçado devido ao conflito bélico na região e à identificação de possíveis relações entre crescimento demográfico e deslocamento forçado. Finalmente a sexta parte reúne as principais conclusões do estudo, destacando as ameaças que sofre a implantação do acordo de paz e a urgência de futuras pesquisas que ampliem o presente estudo.

Este artigo foi elaborado durante o período de professor visitante sênior do autor no Departamento de Geografia da Universidade Nacional da Colômbia, Bogotá, com bolsa da CAPES. 


\section{AMAZÔNIA COLOMBIANA}

Este artigo utiliza como delimitação da Amazônia colombiana aquela definida pelo Instituto Amazónico de Investigaciones Citentíficas (Instituto Sinchi) (GUTIERREZ REY; ACOSTA MUÑOZ; SALAZAR CARDONA, 2004), a qual está integrada pela totalidade dos departamentos de Caquetá, Guaviare e Putumayo, e pelos municípios com território total ou parcial na Amazônia dos departamentos de Cauca (municípios de Piamonte, San Sebastián e Santa Rosa), Nariño (municípios de Córdoba, Funes, Ipiales, Pasto, Potosi e Puerres), e Meta (municípios de La Macarena, Mapiripán, Mesetas, Puerto Concordia, Puerto Gaitán, Puerto Rico, San Juan de Arama, Uribe e Vistahermosa) (Amazônia Ocidental) e pela totalidade dos departamentos de Amazonas, Guainía e Vaupés, e parte do município de Cumaribo, no departamento de Vichada (Amazônia Oriental) (Figura 1). No total, a Amazônia colombiana assim delimitada, compreende 78 municípios incluindo 20 áreas não municipalizadas ou corregimentos (9 em Amazonas, 8 em Guainía e 3 em Vaupés). Essas áreas são territórios sob jurisdição dos departamentos, que mesmo delimitadas geograficamente, o censo só registra população rural. Neste estudo as áreas não municipalizadas são consideradas como se fossem municípios (SALAZAR CARDONA; RIAÑO UMBARELA, 2016).

Figura 1 - A Amazônia colombiana

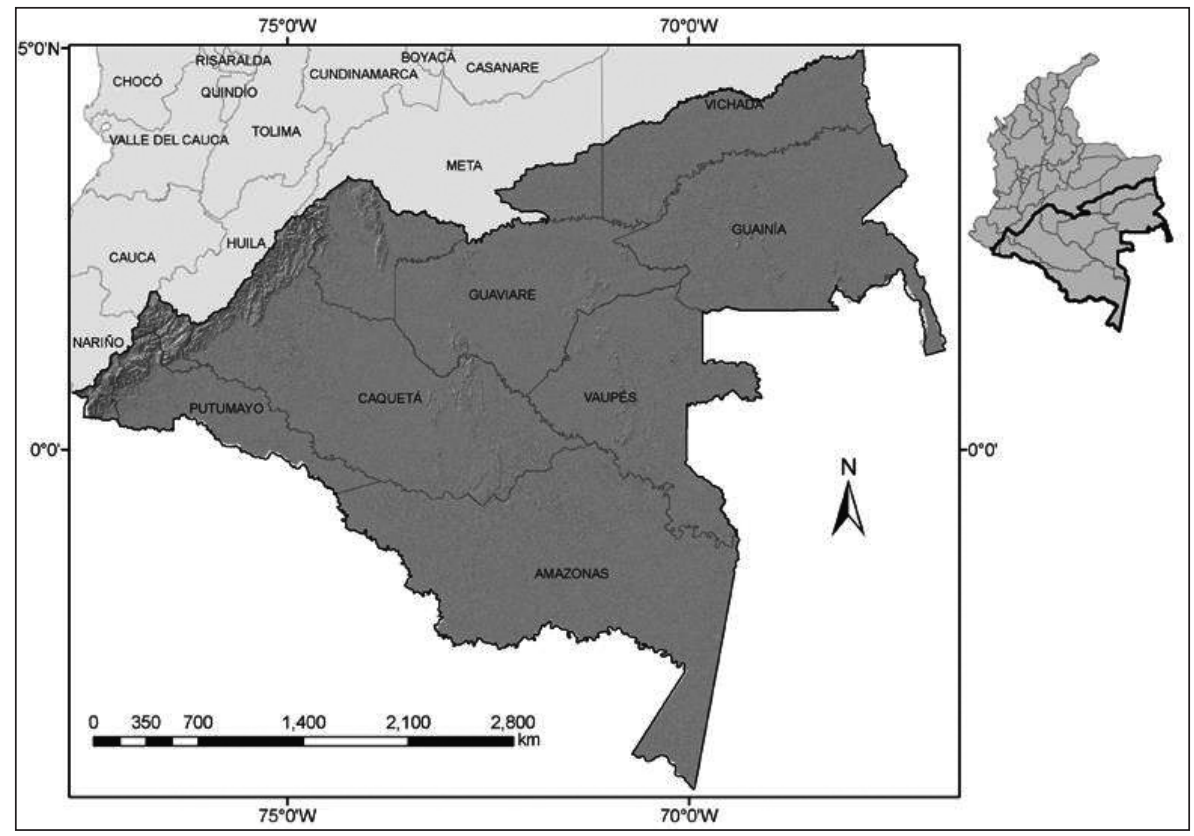

Fonte: Otavo e Murcia (2018, p. 61) 
Conforme a definição do Instituto Sinchi, a Amazônia colombiana cobre uma área de $483.163 \mathrm{~km}^{2}$ (SALAZAR CARDONA; RIAÑO UMBARELA, 2016, p. 26), e o censo de 2018 registra uma população de 1.251 .847 habitantes que representam $42,4 \%$ da área e 2,6\% da população do país.

\section{PROCESSO DE OCUPAÇÃO}

A história da ocupação da Amazônia colombiana é acompanhada de episódios extremamente violentos, conforme se sucedem bonanças extrativas de recursos naturais e se entrelaçam processos de colonização, de cultivos de coca, de narcotráfico, e a guerra travada contra a guerrilha durante mais de cinquenta anos, dentre outros (ARAGÓN, 2013).

Sem se remontar à época da conquista e colônia, os booms extrativos de recursos naturais da Amazônia mais relevantes começam com a exploração da quina, principalmente, para fabricar, da sua casca, remédios contra a malária. Segundo Salazar Cardona (2013), ainda que a sua exportação para Europa remonte ao século 18, o boom econômico da extração da quina na Amazônia colombiana foi de 1850 a 1883, especialmente durante a Guerra de Secessão nos Estados Unidos (1861-1865), quando se exportou grande quantidade para atender a população atingida pelas "febres". Ou seja, foi um ciclo extrativo para atender à demanda internacional do recurso natural, que não resistiu à produção noutros países do mundo oferecida a preços mais competitivos, não deixando riqueza na região.

À depressão regional surgida pela decadência da exploração da quina, segue o boom econômico da extração da borracha, de finais do século 19 até 1914, mas cuja extração prolongou-se, em menor escala, até finais dos anos de 1940. Como aconteceu com o ciclo extrativo da quina, o boom econômico da exploração da borracha obedeceu também à demanda internacional de matériasprimas para produzir material isolante, flexível e impermeável originada pela Revolução Industrial, especialmente após conseguir a vulcanização, e a produção em massa do automóvel. Grandes conglomerados principalmente de países como França, Holanda, Bélgica, Inglaterra e Estados Unidos, exploraram diretamente ou por meio de intermediários, a produção do látex, em toda a Pan-Amazônia que contasse com a presença de árvores de borracha, notadamente no Brasil, na Colômbia, no Peru, na Bolívia e no Equador. As origens de muitos municípios, povoados e cidades amazônicas da Colômbia, especialmente do oeste da região, foram as sedes das agências exploradoras do látex, os seringais, e os centros de recolhimento da produção. Superado pelos preços mais competitivos do látex 
produzido na Ásia, este ciclo encerrou-se definitivamente após a Segunda Guerra Mundial, deixando na região a gênese do povoamento da Amazônia Ocidental, mas também, uma população indígena dizimada e imensas áreas de seringais degradadas (SALAZAR CARDONA, 2013).

A exploração do ouro é outro boom que acompanha a história da ocupação da Amazônia colombiana. Conforme o texto de Salazar Cardona (2013), no século 20, este ciclo foi impulsionado por colonos do departamento de Nariño que durante a primeira metade desse século exploraram ouro de aluvião ao longo dos rios na Amazônia Ocidental, principalmente nas proximidades do atual município de Orito (Putumayo), de onde origina seu nome. Ainda que fora uma exploração efêmera e rudimentar de pequena escala, esta atividade gerou um processo de colonização familiar baseada na exploração desse metal que consolidou o povoamento da zona. Segundo o mesmo autor, mais recentemente, o Oriente amazônico também foi alvo de exploração de ouro. Durante as décadas de 1970 e 1980 foi explorado ouro de filão na serrania de Naquén, no departamento de Guainía. Em 1983 chegaram à área garimpeiros brasileiros que, introduzindo técnicas altamente destrutivas do meio ambiente, ampliaram a produção disputando a exploração do metal com a população indígena do local. Tal situação de conflito originou a criação em 1992 da primeira Reserva Mineral Indígena, forçando os mineradores não indígenas a saírem do local. Não teve a mesma sorte a descoberta de ouro de filão nas serranias de Taraira, no departamento de Vaupés. Entre 1985 e 1989 a exploração do metal na área atraiu pessoas de diversas partes do país e com elas vieram comerciantes que estimularam pequenos garimpeiros a aumentar a produção por meio de endividamento em troca de ferramentas, motobombas e outros instrumentos que aumentaram a degradação ambiental.

A extração de madeiras nobres acompanha a exploração da Amazônia colombiana ao longo de sua história, mas foi a partir de 1940 que a atividade se intensificou com o processo denominado desflore del cedro (SALAZAR CARDONA, 2013), ou seja, desmatamento do cedro, até o ponto de quase desaparecer. O boom extrativo de madeiras nobres, intensificado especialmente entre 1940 e 1960, foi protagonizado principalmente por grandes empresários do setor, que amparados por autorizações sem maior controle por parte do Estado, organizaram e administraram, com recursos próprios, verdadeiras invasões de desmatadores em extensas áreas da floresta amazônica com o intuito de extrair o máximo possível de madeira nobre e transportá-la para os centros consumidores do país. O extrativismo madeireiro se concentrou principalmente nos departamentos do noroeste da Amazônia, aproveitando trilhas, estradas e outras infraestruturas 
construídas em booms anteriores, ampliando-as para interligar as diversas áreas de exploração e com os centros mais importantes do país. Mais tarde essas rotas e infraestruturas foram usadas por colonos espontâneos provenientes na sua maioria da região andina pressionados principalmente pela violência, ampliando a fronteira agrícola e expandindo o povoamento da região. O extrativismo da madeira nobre da Amazônia permanece até hoje e tem avançado em diferentes intensidades até o departamento de Amazonas, no extremo sudeste da região (SALAZAR CARDONA, 2013). Em recente expedição científica, Domínguez (2019) constata essa intensa atividade ao longo da estrada marginal da selva no Oeste da região, principalmente no Sul de Meta e Oeste de Caquetá e Putumayo.

Acompanhando o desmatamento em busca de madeiras nobres, especialmente durante o período do desflore del cedro, surge um boom, conhecido como tigrilleo (SALAZAR CARDONA, 2013), de extração de peles de animais altamente valorizadas no mercado internacional, em especial, de felinos, jacarés, lontras, e outros animais que foram caçados sem misericórdia e sem controle, para comercializar suas peles.

A exploração de petróleo surgiu ainda como outro boom igualmente ou mais depredador que os anteriores. Segundo Salazar Cardona (2013), embora a prospecção na Amazônia remonte aos anos 1930, o boom econômico da exploração petroleira na Amazônia foi gerado na década de 1950 quando a Texas Petroleum Company realizou atividades de prospecção ao redor de Orito, San Miguel, Acaé e Vale de Guamués, no departamento de Putumayo. Nos anos 1960, empresas estrangeiras também fizeram prospecções na serra da Macarena e nas margens do rio Lozada (departamento de Meta), e em San Vicente del Caguán (departamento de Caquetá). A abertura de trilhas de penetração e as expectativas de acesso aos empregos que a exploração de petróleo ofereceria funcionaram como forte atração para a população camponesa da região andina que chegou a essas áreas em busca das oportunidades de trabalho na exploração petroleira. Contudo, por ser um produto ainda estratégico para a economia mundial, argumenta Salazar Cardona (2013), o boom do petróleo permaneceu latente na região amazônica, especialmente em Putumayo. Atualmente a fase depressiva do ciclo dos hidrocarbonetos começa a se reverter, uma vez que outras empresas estrangeiras, em parceria ou em acordo com a Empresa Colombiana de Petróleos (ECOPETROL), a empresa estatal, têm descoberto poços promissores especialmente em Puerto Asís e Villagarzón (Putumayo), aumentando a superlotação da população em suas sedes municipais, em Mocoa (a capital departamental) e outros povoados próximos. 
Quando chegou a crise do petróleo em 1976, surgiu a bonança dos cultivos ilícitos, começando pela maconha num curto período de 1977 a 1979, seguida pela coca, que ainda que com menor intensidade persiste e já alcançou todos os departamentos da região. Mesmo que a produção de maconha na região tenha se concentrado no departamento de Guaviare e sul do departamento de Meta, a sua produção, afirma Salazar Cardona (2013), "pavimentou” a via para o cultivo em grande escala da coca e a produção da pasta básica da cocaína. À raiz da produção de maconha, a circulação de dinheiro aumentou, a produção de alimentos estagnou, o comércio de insumos básicos e de produtos suntuosos cresceu, novas trilhas e rotas de transporte terrestre foram abertas, a oferta de mobilidade fluvial foi aprimorada, e o ambiente natural e ecológico foi gravemente comprometido, facilitando, dessa forma, a entrada e difusão do cultivo de coca para fins ilícitos, e com ela o aumento da violência pela disputa e controle do narcotráfico. Com os altos preços no comércio internacional da pasta básica de cocaína, os cartéis de drogas colombianos promoveram o cultivo de coca e a transformação primária de suas folhas em polpa básica no final da década de 1970, originalmente nos municípios de Miraflores e San José del Guaviare, no departamento de Guaviare, no atual Parque Natural Nacional de La Macarena (departamento de Meta), e nas selvas isoladas do departamento de Vaupés (SALAZAR CARDONA, 2013). A partir desses focos, os cultivos espalharam-se rapidamente para todos os departamentos da Amazônia colombiana.

Segundo os censos da produção de coca no país, elaborados pela Oficina de las Naciones Unidas contra la Droga y el Delito (UNODC), a região amazônica colombiana dominou o cultivo da coca no país até os cinco primeiros anos do século 21 (UNODC, 2019). A partir de 2005, o domínio do cultivo da coca na Amazônia cai paulatinamente. Em 2018 as zonas denominadas pela UNODC como Amazônia (Amazonas, Vaupés e Guainía), Putumayo-Caquetá e Meta-Guaviare, isto é, os seis departamentos totalmente amazônicos mais o departamento de Meta, representavam 27\% (45.683 hectáres) da área cultivada de coca no país (169.000 hectáres). A área cultivada na Amazônia concentrase na denominada zona de Putumayo-Caquetá com 38.170 hectáres (83,6\%), as demais zonas da região cultivam 7.285 hectáres em Meta-Guaviare e 228 hectáres na Amazônia (Amazonas, Vaupés e Guainía), sendo que departamentos como Vaupés e Guainía estão próximos de serem declarados por esse organismo como departamentos livres de cultivos de coca. Mas os focos tradicionais de cultivo mantêm-se. Entre eles, Puerto Asis e Orito em Putumayo permanecem entre os dez municípios do país com maior área de produção de coca (UNODC, 2019). 
Porém, mesmo que a área dedicada a cultivos de coca esteja diminuindo no país, em especial na Amazônia, a produção de folha fresca de coca por hectare, e de pasta básica de cocaína está aumentando, o que significa que "há mais coca em menos território" (UNODC, 2019, p. 11-14), ou seja, que a produção de coca e de cocaína está se aprimorando, melhorando técnicas de cultivo, selecionando melhores espécies e ampliando o narcotráfico.

Não resta dúvida que por muitos anos o povoamento, a infraestrutura de transporte, a urbanização e a economia da região foram regidos pelo cultivo da coca e a produção da pasta básica de cocaína. Foram territórios de produção disputados por guerrilheiros, paramilitares, traficantes e colonos (CIRO, 2018; DUARTE ROJAS; COT'TE POVEDA, 2014), disputas que geraram violência, desmatamento, deslocamento forçado, intimidação, extorção, desterro, enriquecimento ilícito e todo tipo de violação aos direitos humanos e que representam ainda uma ameaça: "Enquanto a coca persistir no território, também persistirão o interesse dos grupos armados, a insegurança, os riscos de corrupção e as restrições à legalidade, o que constitui uma limitação à sustentabilidade" (UNODC, 2019, p. 14).

\section{CRESCIMENTO DEMOGRÁFICO}

Ao longo dos anos permanece uma diferença significativa no tamanho, na distribuição e no ritmo de crescimento da população das Amazônias Ocidental e Oriental. Segundo o censo de 2018, mais de $83 \%$ da população estão distribuídos entre os departamentos da parte ocidental da região, e nesta concentra-se em Caquetá (32,10\%) e Putumayo (27,81\%) (Tabela 1). Com referência à Amazônia Oriental, percebe-se a reduzida população em relação à Amazônia Ocidental. É realmente uma população esparsa com pequenos núcleos destacando Letícia, na tríplice fronteira (Colômbia/Peru/Brasil), capital de Amazonas (SALAZAR CARDONA; RIAÑO UMBARILA, 2016), departamento que alberga um pouco mais de 6\% da população de toda a região e mais de 36\% da sub-região (2018). Destaca-se, também, o departamento de Vichada (município de Cumaribo), que em 2018, a sua população era 20,78\% da população da sub-região.

A distribuição da população, conforme as divisões departamentais, pouco mudou ao longo do tempo. Considerando os quatro últimos censos, a população total da Amazônia passou de 788.043, em 1985, para 1.251.847, em 2018, ou seja, cresceu quase $60 \%$ em 33 anos, sempre concentrada na parte ocidental (Tabela 1). 
Tabela 1 - População total, urbana e rural da Amazônia colombiana, e taxas de crescimento demográfico médio anual, por departamentos, censos de 1985, 1993, 2005 e 2018

\begin{tabular}{l|r|r|r|r|r|r|r}
\hline \multicolumn{1}{c|}{ Departamentos } & \multicolumn{1}{c|}{$\mathbf{1 9 8 5}$} & \multicolumn{1}{c|}{$\mathbf{1 9 9 3}$} & \multicolumn{1}{c}{$\mathbf{2 0 0 5}$} & \multicolumn{1}{c}{$\mathbf{2 0 1 8}$} & \multicolumn{1}{c}{$\mathbf{1 9 8 5 - 1 9 9 3}$} & $\mathbf{1 9 9 3 - 2 0 0 5}$ & $\mathbf{2 0 0 5 - 2 0 1 8}$ \\
\hline \multicolumn{7}{|c|}{ População Total } \\
\hline Amazônia Ocidental & 703.347 & 855.372 & 1.040 .290 & 1.042 .950 & 2,44 & 1,63 & 0,02 \\
\hline Caquetá & 287.047 & 362.636 & 420.518 & 401.849 & 2,91 & 1,23 & $-0,35$ \\
\hline Putumayo & 210.030 & 256.432 & 310.132 & 348.182 & 2,49 & 1,58 & 0,89 \\
\hline Guaviare & 57.396 & 76.680 & 95.551 & 82.767 & 3,60 & 1,83 & $-1,10$ \\
\hline Meta & 59.868 & 70.210 & 98.724 & 88.294 & 1,99 & 2,81 & $-0,86$ \\
\hline Cauca & 12.760 & 20.445 & 23.084 & 19.742 & 5,79 & 1,01 & $-1,20$ \\
\hline Nariño & 76.246 & 68.969 & 92.281 & 102.116 & $-1,25$ & 2,41 & 0,78 \\
\hline Amazônia Oriental & 84.696 & 114.017 & 160.710 & 208.897 & 3,69 & 2,83 & 2,01 \\
\hline Amazonas & 38.004 & 51.398 & 67.726 & 76.589 & 3,75 & 2,28 & 0,94 \\
\hline Vaupés & 22.806 & 30.683 & 39.279 & 40.797 & 3,68 & 2,05 & 0,29 \\
\hline Guainía & 17.871 & 23.869 & 35.230 & 48.114 & 3,59 & 3,20 & 2,38 \\
\hline Vichada & 6.015 & 8.067 & 18.475 & 43.397 & 3,64 & 6,54 & 6,20 \\
\hline Total Amazônia & $\mathbf{7 8 8 . 0 4 3}$ & $\mathbf{9 6 9 . 3 8 9}$ & $\mathbf{1 . 2 0 1 . 0 0 0}$ & $\mathbf{1 . 2 5 1 . 8 4 7}$ & $\mathbf{2 , 5 8}$ & $\mathbf{1 , 7 8}$ & $\mathbf{0 , 3 2}$ \\
\hline Total Colômbia & 30.062 .198 & 37.635 .094 & 42.888 .592 & 48.258 .494 & 2,80 & 1,09 & 0,91 \\
\hline
\end{tabular}

\begin{tabular}{l|r|r|r|r|r|r|r}
\hline \multicolumn{7}{c|}{ População Urbana } & \multicolumn{2}{c|}{ Taxa de crescimento demográfico } \\
\hline Amąônia Ocidental & 239.657 & 306.800 & 451.638 & 516.929 & 3,07 & 3,18 & 1,04 \\
\hline Caquetá & 135.322 & 165.463 & 231.375 & 258.280 & 2,51 & 2,77 & 0,85 \\
\hline Putumayo & 65.541 & 89.411 & 135.616 & 174.539 & 3,85 & 3,42 & 1,93 \\
\hline Guaviare & 21.578 & 30.028 & 49.789 & 45.991 & 4,09 & 4,13 & $-0,61$ \\
\hline Meta & 16.620 & 20.810 & 32.689 & 35.338 & 2,80 & 3,70 & 0,60 \\
\hline Cauca & 596 & 1.088 & 2.169 & 2.781 & 7,30 & 5,53 & 1,90 \\
\hline Nariño & 0 & 0 & 0 & 0 & & - & - \\
\hline Amazônia Oriental & 28.702 & 39.756 & 54.640 & 72.306 & 4,04 & 2,63 & 2,14 \\
\hline Amazonas & 17.340 & 23.983 & 25.659 & 37.047 & 4,02 & 0,56 & 2,79 \\
\hline Vaupés & 5.190 & 7.218 & 13.876 & 12.090 & 4,09 & 5,26 & $-1,06$ \\
\hline Guainía & 5.513 & 7.643 & 10.793 & 20.279 & 4,05 & 2,85 & 4,70 \\
\hline Vichada & 659 & 912 & 4.312 & 2.890 & 4,03 & 10,85 & $-3,04$ \\
\hline Total Amazônia & $\mathbf{2 6 8 . 3 5 9}$ & $\mathbf{3 4 6 . 5 5 6}$ & $\mathbf{5 0 6 . 2 7 8}$ & $\mathbf{5 8 9 . 2 3 5}$ & $\mathbf{3 , 1 8}$ & $\mathbf{3 , 1 2}$ & $\mathbf{1 , 1 6}$ \\
\hline Total Colômbia & 19.628 .427 & 25.848 .890 & 31.886 .605 & 36.424 .653 & 3,42 & 1,74 & 1,02 \\
\hline
\end{tabular}

\begin{tabular}{l|r|r|r|r|r|r|r}
\hline \multicolumn{4}{c|}{ População Rural } & \multicolumn{3}{c}{ Taxa de crescimento demográfico } \\
\hline Amazônia Ocidental & 463.690 & 548.5727 & 588.652 & 526.021 & 2,10 & 0,59 & $-0,86$ \\
\hline Caquetá & 151.725 & 197.173 & 189.143 & 143.569 & 3,26 & -0.35 & $-2,11$ \\
\hline Putumayo & 144.489 & 167.021 & 174.516 & 173.643 & 1,81 & 0,37 & -0.04 \\
\hline Guaviare & 35.818 & 46.652 & 45.762 & 36.776 & 3,28 & $-0,16$ & $-1,67$ \\
\hline Meta & 43.248 & 49.400 & 66.035 & 52.956 & 1,66 & 2,40 & $-1,69$ \\
\hline Cauca & 12.164 & 19.357 & 20.915 & 16.961 & 5,70 & 0,64 & $-1,61$ \\
\hline Nariño & 76.246 & 68.969 & 92.281 & 102.116 & $-1,25$ & 2,41 & 0,78 \\
\hline Amazônia Oriental & 55.994 & 74.261 & 106.070 & 136.591 & 3,51 & 2,94 & 1,94 \\
\hline Amazonas & 20.664 & 27.415 & 42.067 & 39.542 & 3,51 & 3,51 & $-0,48$ \\
\hline Vaupés & 17.616 & 23.465 & 25.403 & 28.707 & 3,56 & 0,66 & 0,94 \\
\hline Guainía & 12.358 & 16.226 & 24.437 & 27.835 & 3,38 & 3,37 & 1,00 \\
\hline Vichada & 5.356 & 7.155 & 14.163 & 40.507 & 3,59 & 5,48 & 7,41 \\
\hline Total Amazônia & $\mathbf{5 1 9 . 6 8 4}$ & $\mathbf{6 2 2 . 8 3 3}$ & $\mathbf{6 9 4 . 7 2 2}$ & $\mathbf{6 6 2 . 6 1 2}$ & $\mathbf{2 , 2 6}$ & $\mathbf{0 , 9 1}$ & $\mathbf{- 0 , 3 6}$ \\
\hline Total Colômbia & 13.433 .771 & 11.786 .204 & 11.001 .987 & 11.833 .841 & 1,63 & $-0,57$ & 0,56 \\
\hline
\end{tabular}

Fonte: Departamento Administrativo Nacional de Estadística (DANE). Censos de população de 1985, 1993, 2005, 2018 (DANE, s.d.).

Nota: A população dos censos é conciliada ajustando falhas de cobertura a 30 de junho do respectivo ano. Os dados ajustados da população amazônica dos municípios amazônicos dos departamentos de Meta, Cauca, Nariño e Vichada, referentes aos censos de 1985, 1993 e 2005, foram reproduzidos de Salazar Cardona e Riaño Umbarila (2016, p. 180-183). Agradece-se aos pesquisadores Elizabeth Riaño Umbarila e Carlos Ariel Salazar Cardona pela realização do ajuste da população amazônica dos municípios amazônicos desses departamentos no censo de 2018. Para o método de cálculo da taxa de crescimento demográfico, consultar Shyrock, Siegel e Stockwell (1976). Para o procedimento de cálculo da superfície e população dos municípios com território parcialmente amazônico, consultar López Castro (2009). 
Com relação à distribuição da população rural e urbana, em toda a região, a população urbana (localizada nas cabeceras municipais) é menor (47,07\%) que a localizada em áreas rurais (localizada no resto do município) (52,93\%) (2018), mas nos dois casos a sua distribuição nos diversos departamentos segue o padrão da população total. Em relação ao país, a população amazônica representa uma pequena parte: $2,59 \%, 1,62 \%$ e $5,60 \%$ da população total, população urbana e população rural do país (2018) (Tabela 1).

As cifras dos últimos quatro censos revelam um ritmo de crescimento descendente generalizado, tanto na população total como na urbana e na rural, na Amazônia Ocidental como na Oriental e praticamente em todos os departamentos.

Como se pode observar na Tabela 1, essa tendência acompanha o ritmo de crescimento do país, que passou de 2,80\% ao ano no período intercensitário de 1985 a 1993 para 1,09\% de 1993 a 2005, e 0,91\% de 2005 a 2018. Comportamento decrescente seguiu também a população urbana do país, e da região, e também a população rural, exceto para o último período (2005-2018), quando o país apresentou crescimento em relação ao período anterior, de $-0,57 \%$ para $0,56 \%$, enquanto a Amazônia continuou com o ritmo descendente, passando de $0,91 \%$ para $-0,36 \%$.

Em nível nacional a recuperação da população rural no último período intercensitário poderia, entre outros fatores, indicar maior retenção da população em áreas rurais como consequência do acordo de paz de 2016? É uma discussão que valeria a pena aprofundar.

$\mathrm{Na}$ Amazônia, no período intercensitário de 1985-1993, a região experimentou suas mais elevadas taxas de crescimento demográfico total (2,58\% ao ano), especialmente a Amazônia Oriental (3,69\%). Nesse período é digno de nota que somente um departamento (Nariño) apresentou crescimento negativo $(-1,25 \%)$. As taxas de crescimento dos departamentos da Amazônia Oriental são mais elevadas que as da Amazônia Ocidental, excetuando Cauca que apresentou o crescimento mais expressivo de todos os departamentos da região (5,79\%). Esses foram anos de alta produção de coca, o que intensificou a colonização da região atraindo gente para trabalhar na sua exploração (ARCILA NIÑO, 2011). No seguinte período (1993-2005), os processos socioeconômicos do período anterior continuam, mas as taxas de crescimento demográfico decrescem, porém ainda se mantendo positivas. Exceção à regra de descenso do crescimento demográfico nesse período são Nariño e Meta, na Amazônia Ocidental, que saltaram de -1,25\% para 2,41\% e de 1,99\% para 2,81\%; e Vichada na Amazônia Oriental, que saltou de 3,64\% para 6,54\% (Tabela 1). 
A tendência decrescente do crescimento demográfico da região continuou no próximo período intercensitário (2005-2018), porém de forma drástica, baixando as taxas a níveis próximos de zero ou negativas, excetuando o departamento de Guainía (2,38\%) e de forma mais expressiva o departamento de Vichada (6,20\%), os dois na Amazônia Oriental. Mesmo assim, nos dois casos, as taxas neste período são inferiores às do período anterior (Tabela 1).

Essa tendência descendente do crescimento demográfico e a queda drástica no último período intercensitário também acontecem quando se toma o crescimento da população das áreas urbanas e rurais, ainda que variando a magnitude dos indicadores.

A população urbana no primeiro período intercensitário (1985-1993) apresentou taxas superiores a 2,5\% em todos os departamentos da Amazônia Ocidental, destacando Guaviare e Cauca, com 4,09\% e 7,30\%, respectivamente. O crescimento nos departamentos da Amazônia Oriental foi ainda mais espetacular superando sempre os 4,00\% ao ano. No segundo período (1993-2005), enquanto a Amazônia Ocidental apresentou pouca mudança nas magnitudes das taxas, a Amazônia Oriental apresentou quedas significativas, excetuando-se Vichada, que passou de 4,03\% para 10,85\% (Tabela 1). Durante esses períodos é quando a Amazônia colombiana se urbaniza. Fortalece-se e amplia-se o que Domínguez (2001) chama de "anel de povoamento da Amazônia". É um processo que se amplia para toda a Pan-Amazônia, gerando uma zona de povoamento consolidado (BECKER, 2004) que avança para o interior da região.

No último período (2005-2018), a queda da taxa de crescimento da população urbana é acentuada, especialmente na Amazônia Ocidental, chegando a crescimento negativo em Guaviare (-0,61\%), após experimentar crescimento de 4,13\% no período anterior. A Amazônia Oriental apresentou descenso significativo, porém, não nas mesmas dimensões que a Amazônia Ocidental, ainda que destacando importante crescimento de Amazonas (de 0,56\% para $2,79 \%$ ) e de Guainía (de 2,85\% para 4,70\%), mas uma queda espetacular de Vichada (de 10,85\% para -3,04\%) e de Vaupés (de 5,26\% para -1,06\%) (Tabela 1).

E a população rural como se comporta? Primeiramente deve-se destacar que o território amazônico do departamento de Nariño somente contribui com população rural, portanto as taxas de crescimento da população rural são as mesmas da população total. O primeiro período (1985-1993), assim como a população total e a população urbana, a população rural apresenta taxas elevadas de crescimento, especialmente na Amazônia Oriental, sempre acima de 3\%. A 
Amazônia Ocidental, com taxas inferiores, apresenta dois destaques: Nariño, com taxa negativa (-1,25\%) e Cauca, com uma taxa extraordinária de 5,70\%. No segundo período (1993-2005), as taxas de crescimento da população rural caem, especialmente na Amazônia Ocidental, chegando a ser negativas em Caquetá e Guaviare e próximas de zero em Putumayo e Cauca. Crescimento significativo apresenta-se em Meta de 1,66\% para 2,40\% e em Nariño de -1,25\% para 2,41\%. A Amazônia Oriental ainda apresenta taxas relativamente elevadas da população rural, exceto em Vaupés $(0,66 \%)$. Crescimento expressivo em Vichada que passou de 3,59\% para 5,48\%. A queda brusca se dá no último período (20052018), especialmente na Amazônia Ocidental, onde todos os departamentos apresentaram taxas negativas de crescimento da população rural, exceto Nariño com taxa próxima de zero. Já a Amazônia Oriental, mesmo com importante queda das taxas, só Amazonas apresentou taxa negativa (-0,48\%). Registrou-se crescimento insignificante em Vaupés, e crescimento espetacular em Vichada, que passou de 5,48\% para 7,41\% (Tabela 1 ).

Essas cifras permitem concluir que: 1) Ao longo de 33 anos (19852018) a Amazônia colombiana apresenta uma tendência descendente constante de seu ritmo de crescimento, tanto da população total quanto da população urbana e rural. Essa tendência se dá praticamente em todos os departamentos da região; 2) Ainda que essa tendência se mantenha, as taxas de crescimento tendem a ser maiores nos departamentos da Amazônia Oriental; 3) A tendência decrescente se agudiza no último período intercensitário (2005-2018) quando as taxas baixam a níveis ao redor de 1\% ou se tornam negativas, com raras exceções; 4) Nesse processo se destaca o departamento de Vichada (município de Cumaribo). Apresenta uma elevadíssima taxa de crescimento da população total, mas concentrando primeiro esse crescimento na população urbana, e no último período na população rural, chegando inclusive a perder população urbana.

Esse comportamento demográfico resulta de múltiplos processos entre os quais se destacam os enunciados no item que tratou da ocupação da região. É fato que a queda do ritmo de crescimento demográfico da Amazônia vinha ocorrendo desde longo tempo, porém, a queda drástica desse crescimento no último período intercensitário é difícil de explicar perante as modificações sociais e econômicas esperadas com a assinatura do acordo de paz de 2016. Efetivamente, o acordo de paz assinado em 24 de novembro de 2016 e intitulado "Acuerdo final para la terminación del conflicto y la construcción de una paz estable y duradera" (Acordo final para o término do conflito e a construção de 
uma paz estável e durável) (COLOMBIA, 2018), um documento de 310 páginas que integra uma série de acordos específicos que cobrem diversos aspectos da economia, da sociedade, do meio ambiente, da política, dos vitimados, e outros, prevê, entre outros muitos propósitos, promover uma Reforma Rural Integral, Planos de Desenvolvimento Integral com Enfoque Territorial (PDET), Políticas de Reparação às Vítimas do conflito, medidas sobre Restituição de Terras e Retorno de Deslocados Forçados. Determina ainda que "os efeitos do conflito sejam revertidos, que as vítimas de desapropriação e deslocamento forçado e seus direitos a terra sejam restaurados às comunidades e que ocorra o retorno voluntário de mulheres e homens deslocados". Nessa perspectiva alguns previam mudanças significativas dos padrões migratórios do país incluíndo o retorno de população rural às terras desapropriadas e anteriormente controladas pela guerrilha (SALAZAR et al., 2018).

Portanto, com o fim do conflito bélico na Amazônia, esperava-se que o processo de queda do ritmo de crescimento se invertesse, ou se estabilizasse no último período intercensitário (2005-2018). Isto é, que a população no censo de 2018 apresentasse uma elevação significativa em relação àquela de 2005. De fato, os dados não revelam tal perspectiva, pois nesse período a Amazônia ganhou no total somente 2.660 pessoas $(0,26 \%)$. Pelo contrário, a queda das taxas de crescimento entre 2005 e 2018 foi enorme em relação aos períodos anteriores. Ou seja, a queda do ritmo de crescimento aprofundou-se ao invés de se atenuar.

Explora-se a seguir a possível relação entre essa queda do crescimento demográfico e a implantação do acordo de paz na região. O que se especula aqui é que os efeitos do acordo de paz assinado entre o governo colombiano e as FARCEP em 2016, em termos de estímulo a reocupação da região, não têm trazido até agora os resultados esperados, dando margem à continuação de processos de expulsão em curso, levando até mesmo à sua intensificação (SALCEDO RAMÍREZ, 2019). A expulsão da população continua, na medida em que a especulação das melhores terras aumenta gerando o que alguém chamou de uma "ocupação sem povoamento" (SALAZAR CARDONA; RIAÑO UMBARILA, 2016). Um corolário a este processo é a reorganização de grupos armados em diferentes pontos do país, inclusive na Amazônia, como informa o Instituto de Estudios para el Desarrollo y la Paz (INDEPAZ, 2018).

\section{REFLEXOS DO FIM DO CONFLITO BÉLICO?}

Buscando identificar as relações entre o crescimento demográfico da Amazônia colombiana e os processos derivados da implantação do acordo de 
paz assinado em novembro de 2016, apresenta-se a seguir a associação entre as taxas de crescimento demográfico no período intercensitário de 2005 a 2018, quando as quedas das taxas de crescimento demográfico foram mais drásticas, e dados do deslocamento forçado da população nesse período. A quantidade de deslocados é um dos indicadores da magnitude do conflito bélico e revela um dos seus aspectos mais cruéis (CEBALLOS BEDOYA, 2013).

Em nível nacional, a Colômbia é um dos países com maior deslocamento forçado do mundo (ACNUR, 2019, p. 6). Conforme dados oficiais, em nível regional, no mínimo, um total de 533.859 pessoas foram expulsas de seus lugares na Amazônia entre 2005 e 2018, segundo registros do Instituto SINCHI e da Unidad para la Atención y Reparación Integral de las Víctimas (SINCHI, 2020; UATRIV, 2020). Os mais elevados números de expulsões deram-se entre 2005 e 2008, com mais de 60.000 pessoas por ano. Registra-se queda significativa em 2009, de mais de 68.000 em 2008, para cerca de 40.000 em 2009, e posteriormente, outra queda importante em 2016, de cerca de 25.000 em 2015, para quase 11.000 em 2016, chegando a 5.512 expulsos em 2018 (Figura 2A). Esses três períodos (2005-2008, 2009-2015 e 2016-2018) refletem diferentes fases do conflito bélico e tentativas variadas de negociações de paz. O primeiro período reflete a intensidade do conflito armado ainda presente na região pós-fim da zona de desmilitarização (zona de distensión) em 2002. A zona de desmilitarização foi criada em 1998 durante o governo de Andrés Pastrana, que governou o país de 1998 a 2002, com a finalidade de estabelecer negociações de paz com as FARC-EP. Foi uma área sem a presença de forças militares do governo onde as FARC-EP exercitaram relativa autonomia políticoadministrativa. A zona de distensión compreendia uma área de aproximadamente $42.000 \mathrm{~km}^{2}$ e abarcava os municípios de La Macarena, Mesetas, Uribe e Vistahermosa, no departamento de Meta; e San Vicente del Caguán, no departamento de Caquetá. Mas ao contrário do que se esperava, o deslocamento forçado, a extorsão, a violência, o recrutamento forçado, e outras violações dos direitos humanos intensificaram-se nessa zona e em todo o país (GARZÓN-GARZÓN, 2015). Esses e outros fatores fizeram fracassar as negociações de paz, encerrando a zona de distensión em 2002, ainda no governo Pastrana, voltando a área a ser controlada pelo exército nacional (VÁSQUEZ, 2014). Em 2002 toma pose um novo presidente da república, Álvaro Uribe, que governou até 2010, e quem lança a mais forte ofensiva para acabar militarmente com as FARC-EP. Os cinco municípios que integravam a zona de desmilitarização expulsaram 18,5\% do total de $291.501 \mathrm{em}$ toda a região nesse primeiro período (2005-2008) (SINCHI, 2020; UATRIV, 2020). 
Figura 2 - Número de deslocados forçados expulsos de municípios amazônicos no período 2005-2018

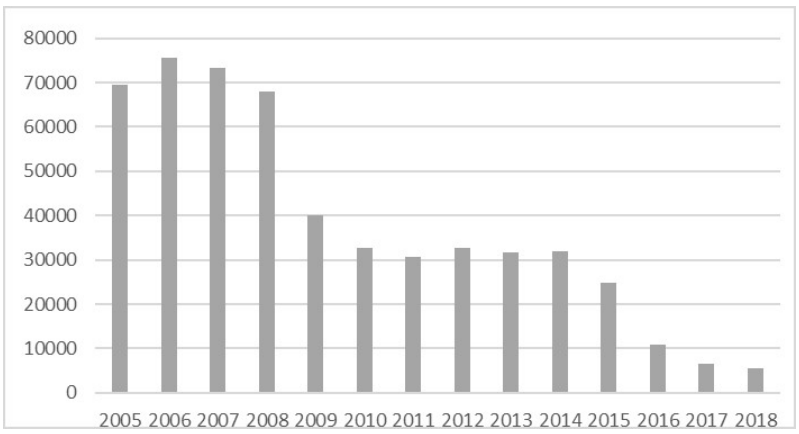

\section{A - Por ano}

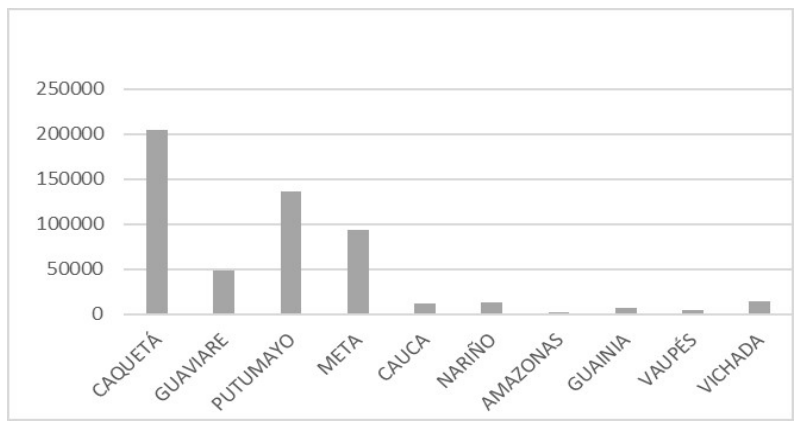

B - Por departamento

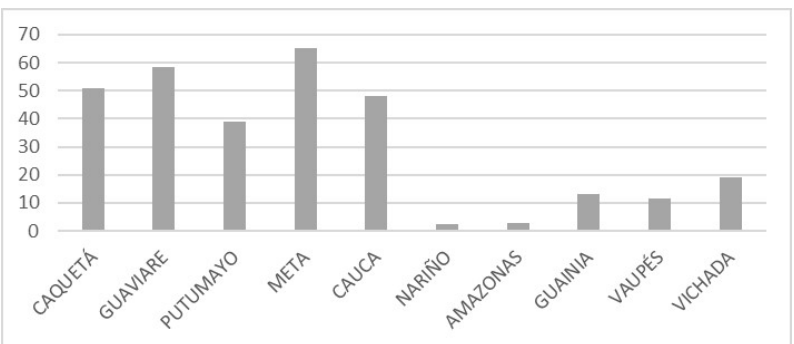

C - Razão de intensidade da expulsão por departamento

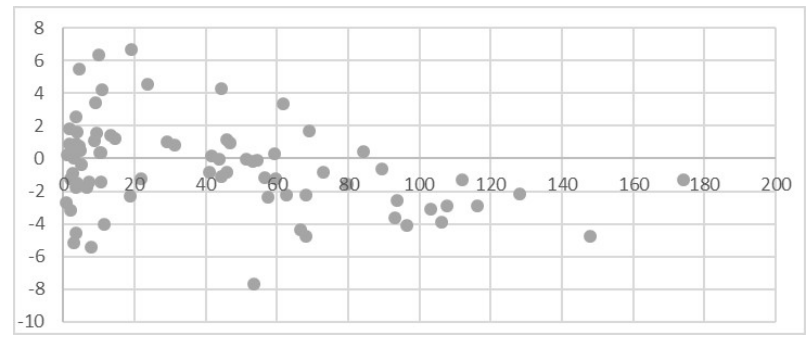

D - Taxa de crescimento dos municípios e intensidade da expulsão

Fonte: Elaboração própria com base nos dados da Unidad para la Atención y Reparación Integral de las Víctimas (UATRIV, 2020). Arquivo gerado pelo Sistema INIRIDA do Instituto Amazónico de Investigaciones Científicas SINCHI (SINCHI, 2020). 
O segundo (2009-2015) e o terceiro período (2016-2018) são reflexos das negociações de paz do novo governo de Juan Manuel Santos (2010 a 2018). Já em 2009, ainda no governo de Uribe, o número de expulsos começa a cair, mas ainda se mantém elevado. Com o avanço das negociações de paz o número anual de expulsos se reduz e se estabiliza, até o final do período quando fica pronto o acordo de paz para ser assinado, e ratificado, o que finalmente acontece em novembro de 2016. Esse último período (2016-2018), que deverá prolongar-se até data não definida, poderia ser denominado de período de implantação do acordo, e é quando o número de expulsos chega ao valor mínimo de todo o período considerado (2005-2018).

No período estudado (2005-2018), todos os departamentos da Amazônia colombiana, em maior ou menor grau, têm sido afetados pelo flagelo do deslocamento forçado. A diferença do número de expulsos por departamentos é de certa forma explicada pelas áreas de maior atuação das FARC-EP na Amazônia Ocidental (OCPDH, 2015). Como se pode observar na Figura 2B, são os seis departamentos da Amazônia Ocidental os que têm apresentado os maiores números. Durante o período 2005-2018, só o departamento de Caquetá concentrou mais de 200.000 expulsos, mas os números de Putumayo, Meta e Guaviare também não são baixos.

É notória a diferença que apresentam os quatro departamentos da Amazônia Oriental (Amazonas, Guainía, Vaupés e Vichada), que exibem números bem inferiores em comparação aos da Amazônia Ocidental. Destacase, entretanto, Vichada, que na realidade refere-se somente ao município de Cumaribo. Apesar de representar somente 2,59\% dos deslocados da região como um todo, os 13.843 deslocados desse departamento representam mais de 50\% dos deslocados da Amazônia Oriental (SINCHI, 2020; UATRIV, 2020).

Para controlar a influência do tamanho populacional, calculou-se a razão de intensidade da expulsão (SALAZAR CARDONA, 2013, p. 50). A razão de intensidade da expulsão é a divisão do número de expulsos acumulados ao longo dos anos desde 2005, pela população total do departamento ou município em 2018, multiplicado por 100. Nota-se que a intensidade da expulsão é maior nos departamentos da Amazônia Ocidental (Figura 2C). Destaca-se Cauca, que mesmo só incluindo três municípios apresentou uma intensidade de quase 50, apesar de o número absoluto de expulsos ser bem menor em relação aos demais departamentos da sub-região. Ou seja, de cada 100 habitantes registrados pelo 
censo de 2018, entre 2005 e 2018, sofreram deslocamento forçado cerca de 50 pessoas. Altas intensidades são também apresentadas por Guaviare, Meta, Caquetá e Putumayo. Esses departamentos foram focos de intensos conflitos bélicos (OCPDH, 2015; RODRÍGUEZ GONZÁLEZ, 2014), e ainda se reportam dissidências da guerrilha e conflitos violentos (INDEPAZ, 2018). Na Amazônia Oriental também a participação de Vichada se torna mais evidente. Apesar de apresentar intensidade menor que nos departamentos de maior intensidade do oeste da região, Vichada apresentou a mais alta intensidade da Amazônia Oriental (próxima de 20). Efetivamente, Cumaribo é um município de história conturbada que permaneceu sob o domínio da guerrilha durante muito tempo (OCPDH, 2015).

Mas será que existe relação entre crescimento demográfico e expulsão de deslocados forçados? Para buscar essa associação utilizaram-se as taxas de crescimento demográfico médio anual no período de 2005 a 2018, e a razão de intensidade da expulsão em nível municipal durante esse período. A Figura 2D deixa ver que há certa associação inversa entre as duas variáveis. Isto é, aqueles municípios que experimentaram menor intensidade permitiram que suas populações crescessem mais em relação àqueles onde a expulsão foi mais intensa. Aparecem, inclusive, oito municípios (Curillo, La Montañita, Milán e Solita em Caquetá; Mapiripán, Puerto Rico e Vistahermosa em Meta; e Miraflores em Guaviare) que apresentaram razões de intensidade extremamente altas, mais de 100, o que significa dizer que a expulsão acumulada foi mais elevada que a população total em 2018. E outros quatro municípios (San José del Fragua, Solano e Valparaiso em Caquetá; e El Retorno, em Guaviare) que apresentaram razões de intensidade próximas de 100. Todos esses doze municípios apresentaram crescimento demográfico negativo. No outro extremo, quatro municípios (Inírida em Guainía; Taraira em Vaupés; Puerto Gaitán em Meta; e Mocoa em Putumayo) apresentaram taxas de crescimento demográfico muito elevadas (acima de 3\%) e intensidade da expulsão até 11. Contudo, há exceções, isto é, municípios com baixo crescimento, até negativo, também com baixa intensidade da expulsão, como por exemplo, La Chorrera e La Victória em Amazonas; Cacahual e Puerto Colombia em Guainia; e Pacoa em Vaupés, que apresentaram taxas negativas de crescimento e razão de intensidade menor que 5. Conclui-se, pois, que, em geral, aqueles municípios onde a expulsão foi menos intensa, o crescimento demográfico foi mais elevado, mantendo exceções. 


\section{CONCLUSÕES}

Pretendeu-se neste artigo, mais que explicar, explorar possíveis relações entre a implantação do acordo de paz com as FARC-EP e a queda do ritmo de crescimento da população da região amazônica colombiana. Nesse sentido, enumeram-se, a seguir, os pontos mais relevantes identificados no estudo os quais incitam análises mais aprofundadas e conclusivas.

A queda do ritmo de crescimento da Amazônia vem ocorrendo faz muito tempo, mas se acentuou grandemente no último período intercensitário (20052018). Esperava-se, pelo contrário, um aumento significativo da população no censo de 2018. Efetivamente neste censo a região ganhou somente 0,26\% da população de 2005. Deduz-se, portanto, que as pessoas não estão retornando às áreas anteriormente ocupadas pela guerrilha, deixando suas terras em mãos de especuladores, latifundiários e pecuaristas. Vale a pena aprofundar.

$\mathrm{O}$ estudo mostrou certa associação inversa entre taxas de crescimento e intensidade da expulsão de deslocados forçados entre os municípios amazônicos. De certa forma isso quer dizer que naqueles municípios onde a expulsão de deslocados forçados foi mais intensa, a recuperação de sua população foi menor, e até negativa, o que significa que a região permanece como uma área de expulsão. É fundamental buscar explicações para a queda drástica do crescimento demográfico em múltiplos fatores, incluindo, entre outros, processos históricos de povoamento, reorganização dos grupos armados, produção de coca, narcotráfico, e dificuldades na implantação do acordo de paz (SALCEDO RAMÍREZ, 2019).

A queda do número de deslocados forçados ao longo dos anos é um fato visível. Tal queda acompanha os diversos esforços para conseguir a paz na Colômbia, especialmente durante o governo de Juan Manuel Santos (2010-2018), quando se intensificam as negociações de paz com as FARC-EP, conseguindo finalmente assinar um acordo em novembro de 2016. Se se considerar somente a queda do número de deslocados forçados poder-se-ia concluir que efetivamente o acordo de paz teve êxito.

Por outro lado, nota-se que as expulsões não terminaram. E não somente expulsos, mas também assassinatos de líderes comunitários e ex-combatentes, reorganização de grupos guerrilheiros e recrutamentos forçados (PERILLA DAZA, 2020). Segundo a Comisión Colombiana de Juristas (CCJ) e outros organismos (CCJ et al., 2018), entre 1 de janeiro de 2016 e 31 de julho de 2018, 
foram registradas no país 343 violações ao direito à vida de líderes sociais e defensores de direitos humanos relacionadas com o conflito armado, 257 das quais ocorreram após o 24 de novembro (data da assinatura do acordo). Igualmente o relatório de 2020 do Human Rights Watch (HRW, 2020), reporta que em 2019 o número de dissidentes das FARC-EP chegava a mais de 2.300, e a 33.000 o número de deslocados forçados no país entre janeiro e julho desse ano, e segundo um informe do Secretário Geral da Organização das Nações Unidas (ONU, 2019), o recrutamento forçado especialmente de crianças e adolescentes segue ativo após o acordo de paz. Conforme esse informe, entre 2017 e 2018 , 361 crianças e adolescentes foram recrutados forçosamente na Colômbia, sendo 169 em 2017 e 293 em 2018.

Tudo isso quer dizer que a implantação do acordo não tem conseguido até agora alcançar muitos dos anseios almejados, ou que é difícil avaliar seu real impacto em tão curto período de tempo. Segundo Salcedo Ramírez (2019, p. 174), o acordo busca de maneira duradoura a articulação de esforços reparadores de vítimas em garantir seus direitos à verdade, justiça, reparação e não repetição, com os processos de reincorporação na vida civil de ex-combatentes, com componentes da justiça restaurativa e retributiva e com as dívidas históricas da justiça social em reforma rural, democratização política e solução do problema das drogas ilícitas. A "Paz Territorial", entre outros fatores, é a estrutura prometida para facilitar o retorno das vítimas do deslocamento e desapropriação de suas terras no âmbito dos Planos de Desenvolvimento com Enfoque Territorial (PDET). Porém, atenção especial deve ser dada à implantação do acordo para controlar fenômenos em curso que atentam contra ele, podendo levá-lo ao fracasso e ao recrudescimento da violência e da guerra.

$\mathrm{Na}$ análise de Salcedo Ramírez (2019, p. 176), apesar do acordo de paz assinado com as FARC-EP, na prática, aprofunda-se no país um modelo de agronegócio que concede direitos de exploração e propriedade a grandes empresas pelo usufruto dos territórios baldios que deveriam ser concedidos aos camponeses sem terra do país. O autor complementa ainda que o aprofundamento desse modelo agroindustrial está se consolidando em várias áreas de desapropriação sem os processos de restituição de terras, ou onde estes processos são muito lentos e mostram poucos resultados. Igualmente, o avanço da mineração na região é promovido pelo governo nacional, inclusive em áreas de restituição e de potencial retorno, o que ameaça as possibilidades de um retorno seguro e digno 
dos deslocados (SALCEDO RAMÍREZ, 2019). Nesse sentido, somente estudos futuros poderão avaliar o real sucesso do acordo de paz.

Finalmente, o deslocamento forçado revela somente um fato da crueldade da guerra. A violência, os assassinatos, o recrutamento forçado, os sequestros, as violações, as extorsões, a invasão de propriedades, e outros fenômenos que atentam contra a dignidade humana, devem ser também considerados e analisados para entender melhor o fato de a Amazônia colombiana permanecer ainda como uma região de expulsão e baixo crescimento demográfico.

\section{REFERÊNCIAS}

ACNUR. Tendencias globales: desplazamientos forzados. Ginebra: ACNUR, 2019.

ARAGÓN, L. E. Amazônia, conhecer para desenvolver e conservar: cinco temas para um debate. São Paulo: Hucitec, 2013.

ARCILA NIÑO, O. H. Amazonia colombiana urbanizada: un análisis de sus asentamientos humanos. Bogotá: Instituto Amazónico de Investigaciones Científicas (SINCHI), 2011.

BECKER, B. K. Amazônia: mudanças estruturais e tendências na passagem do milênio. In: MENDES, A. D. (org.). Amazônia: terra e civilização. Belém: Banco da Amazônia, 2004. p. 115-140.

CCJ et al. ¿Cuáles son los patrones? Asesinatos de líderes sociales en el post acuerdo. Bogotá: CCJ: CINEP: IEPRI, 2018. Disponível em: https://www.cinep.org. $\mathrm{co} /$ publicaciones/es/producto/cuales-son-los-patrones-asesinatos-de-lideressociales-en-el-post-acuerdo/. Acesso em: 23 maio 2020.

CEBALlOS BEDOYA, M. A. El desplazamiento forzado en Colombia y su ardua recuperación. Araracuara: Revista Iberoamericana de Filosofía, Política y Humanidades, Sevilla (España), año 15, n. 29, p. 169-188, 2013.

CIRO, A. Lucha contra las drogas, ganadería, conflicto armado y minería: claves para entender el desplazamiento en la Amazonía Occidental. A la Orilla del Rio, Florencia (Caquetá, Colombia), 26 oct. 2018. Economía, poder y sociedad. Disponível em: http:/ / alaorilladelrio.com/2018/10/26/lucha-contra-las-drogasganaderia-conflicto-armado-y-mineria-claves-para-entender-el-desplazamientoen-la-amazonia-occidental/. Acesso em: 29 jan. 2020. 
COLOMBIA. Oficina del Alto Comisionado para la Paz. Acuerdo final para la terminación del conflicto y la construcción de una paz estable y duradera 24 nov. 2016. Bogotá: Oficina del Alto Comisionado para la Paz, 2018. Disponível em: http://www.altocomisionadoparalapaz.gov.co/Documents/proceso-paz-farcacuerdo-final.pdf. Acesso em: 2 abr. 2020.

DANE. Censo de Población de 1985, 1993, 2005, 2018. DANE, Bogotá, s.d. Disponíveis em: www.dane.org.co. Acesso em: 2 abr. 2020.

DOMÍNGUEZ, C. Se urbaniza la Amazonia? El anillo de poblamiento amazónico. Iniciativa Amazónica: Revista Trimestral de los Países de la Amazonia, Quito (Ecuador), n. 1, 2001.

DOMÍNGUEZ, C. La marginal de la selva en Colombia: dilemas para el trópico húmedo. Bogotá: Universidad Externado de Colombia, 2019.

DUARTE ROJAS, A. M.; COTTE POVEDA, A. Conflicto armado, despojo de tierras y actividad ganadera: indagando entre el testimonio no oficial y las cifras estatales en el departamento del Meta - Colombia. Revista Iberoamericana de Estudios del Desarrollo, Zaragoza (España), v. 3, n. 1, p. 32-57, 2014.

GARZÓN-GARZÓN, L. P. Incidencia del conflicto armado en el desarrollo regional de la Amazonia colombiana. Revista DELOS - Desarrollo Local Sostenible, Málaga (España), v. 8, n. 22, p. 1-25, 2015.

GUTIÉRREZ REY, F; ACOSTA MUÑOZ, L. E.; SALAZAR CARDONA, C. A. Perfiles urbanos en la Amazonia colombiana: un enfoque para el desarrollo sostenible. Bogotá: Instituto Amazónico de Investigaciones Científicas (SINCHI), 2004.

HWR. World report 2020 - Events of 2019. New York: HWR, 2020. Disponível em: https://reliefweb.int/sites/reliefweb.int/files/resources/hrw_world_report _2020.pdf. Acesso em: 1 jun. 2020.

INDEPAZ. Conflictos armados localizados: informe sobre grupos armados ilegales, Colombia 2017-2018. Bogotá: Indepaz, 2018. Disponível em: http:/ /www. indepaz.org.co/wp-content/uploads/2018/12/ConflictosArmadosFocalizadosIndepaz-4.pdf. Acesso em: 23 maio 2020.

LÓPEZ CASTRO, M. O. Dinámicas espaciales y temporales del componente demográfico de la región amazónica colombiana. Bogotá: Instituto Amazónico de Investigaciones Científicas (SINCHI), 2009. 
OCPDH. Atlas del impacto regional del conflicto armado en Colombia: dinámicas locales y regionales en el período 1990-2013. Bogotá: Imprenta Nacional, 2015.

ONU. Los niños y los conflictos armados. Informe del Secretario General: A/73/907 S/2019/509. New York: ONU, 2019. Disponível em: https:// reliefweb.int/sites/reliefweb.int/files/resources/N1918624.pdf. Acesso em: 23 maio 2020.

OTAVO, S.; MURCIA, U. La Amazonia se quema: detección de áreas con mayor ocurrencia de incendios de vegetación como estrategia para la prevención y control. Revista Colombia Amazónica, Bogotá, n. 11, p. 59-72, 2018.

PERILLA DAZA, D. C. La producción de conocimiento sobre la paz en Colombia: verdad, poder y resistencia desde lo local. 2020. Tese (Doutorado em Antropologia) - Programa de Pós-Graduação em Antropologia, Universidade Federal do Rio Grande do Sul, Porto Alegre, 2020.

RODRÍGUEZ GONZÁLEZ, I. Despojo, baldíos y conflicto armado en Puerto Gaitán y Mapiripán (Meta, Colombia) entre 1980 y 2010. Estudios SocioJurídicos, Bogotá, v. 16, n. 1, p. 315-342, 2014.

SALAZAR CARDONA, C. A. Migración interna en la Amazonia colombiana: entre las bonanzas y la violencia. In: ARAGÓN, L. E. (org.). Migração interna na Pan-Amazônia. Belém: Editora do NAEA, 2013. p. 31-55.

SALAZAR CARDONA, C. A.; RIAÑO UMBARILA, E. Perfiles urbanos en la Amazonia colombiana 2015. Bogotá: Instituto Amazónico de Investigaciones Científicas (SINCHI), 2016.

SALAZAR, A.; SANCHEZ, A.; VILLEGAS, J. C.; SALAZAR, J. F.; RUIZ CARRASCAL, D.; SITCH, S.; RESTREPO, J. D.; POVEDA, G.; FEELY, K. J.; MERCADO, L. M.; ARIAS, P. A.; SIERRA, C. S.; URIBE, M. del R.; RENDÓN, A. M.; PÉREZ, J. C.; TORTAROLO, G. M.; MERCADO-BETTINA, D.; POSADA, J. A.; ZHUANG, Q.; DUKES, J. S. The ecology of peace: preparing Colombia for new political and planetary climates. Frontiers in Ecology and the Environment, Washington, D. C. (USA), v. 16, p. 1-7, 2018.

SALCEDO RAMÍREZ, J. A. Las políticas del retorno de los desplazados en el Acuerdo de Paz con las FARC-EP en contexto histórico e internacional: cambios, continuidades y desafíos. Revista Paz y Conflictos, Granada (España), v. 12, n. 1, p. 159-282, 2019. 
SHYROCK, H. S.; SIEGEL, J. S.; STOCKWELL, E. G. The methods and materials of demography. Cambridge, Massachusetts (USA): Academic Press, 1976.

SINCHI. Consulta ao Sistema INIRIDA - Instituto Amazónico de Investigaciones Científicas SINCHI. SINCHI, Bogotá, 2020. Disponível em: http:/ /www.sinchi. org.co/inirida/. Acesso em: 2 abr. 2020.

UATRIV. RNI - Red Nacional de Información. UATRIV, Bogotá, 2020. Disponível em: https//cifras.unidadvictimas.gov.co/. Registros de 1987 a 2018. Acesso em: 2 abr. 2020.

UNODC. Colombia: monitoreo de territorios afectados por cultivos ilícitos 2018. Bogotá: UNODC/SIMCI, 2019.

VÁSQUEZ, T. El papel del conflicto armado en la construcción y diferenciación territorial de la región de "El Caguán", Amazonia Occidental, Colombia. El Ágora USB: Revista de Ciencias Sociales, Medellín (Colombia), v. 14, n. 1, p. 147-175, 2014. 
